\author{
Professor Yusuf Ekrem AKBAS, PhD \\ E-mail: akbasyea@gmail.com \\ Adıyaman University \\ Professor Canan SANCAR, PhD \\ E-mail: canansancar@gumushane.edu.tr \\ Gümüşhane University
}

\title{
THE EFFECT OF INTEREST RATE ON OUTPUT LEVEL AND INFLATION IN TURKEY: EVALUATION OF MONETARIST AND NEW KEYNESIAN PERSPECTIVE
}

\begin{abstract}
In this paper, the relationship between inflation-interest rate and output level for the period between 2000M1-2015M12 in Turkey is evaluated in terms of Monetarist and New Keynesian perspective. These relationships among the variables are analysed through linear and non-linear methods. As a result of the analysis, it is concluded that the interest rate does not have a significant effect on the output level. Also, it was determined that there is a short-term as well as a long-term negative relationship from the interest rate towards inflation. It was concluded that the monetary policy cannot affect the real output, but the inflation. These results show that the Monetarist perspective is more valid for the post 2000 period in Turkey.

Keywords: Inflation rate, interest rate, New Keynesian Perspective, Monetarist Perspective, Non-linear Autoregressive Distributed Lag model.
\end{abstract}

\section{JELClassification: E52, E43, C22, C51.}

\section{Introduction}

The function of the monetary policy is differently evaluated by the Monetarists and the New Keynesians. In the New Keynesian aproach, the interest rate is the most important instrument of the monetary policy. The monetary policy implementations will be effective on the real economy to the extent the interest rates can affect. According to the monetarist approach, the monetary policy has an important role on price level.

The aim of this study is to determine the effect ofinterest rateon inflation and output level in Turkey. In this respect, the effect of monetary policy on output level and inflation is evaluated. Also, it is aimed to determine which approach, the Monetarist or New Keynesian, is more valid. Therefore, it was attempted to determine whether the policy interest is effective either on output level or on inflation rate in Turkey. 
The Effect of Interest Rate on Output Level and Inflation in Turkey: Evaluation of Monetarist and New Keynesian Perspective

Since there was a global economic crisis in the period the study covers, there might be some structural breaks on the series of the variables in the model. Therefore, the econometric methods that take the structural breaks into consideration are used. In addition to this, since the interest rate and inflation can be influenced by many internal and external factors, they may have a non-linear process. Therefore, appropriate econometric methods are used after determining the existence of the non-linear processes in the study.

The organization of the paper is as follows: In the second part, there is a lirerature about Monetarist and New Keynesian approach. In the third part, there is theoretical background for the Monetarist and the New Keynesian approach. In the fourth part, the data and the methods used in the study can be found. In the fifth part, there are the empirical findings and in the last part, there is a section for the results and policy recommendations.

\section{Literature Review}

The studies supporting the results of the Monetarist approach ${ }^{1}$ are based on the study of Friedman and Schwartz (1963). In these studies, the relationship between monetary variables and Nominal GDP was analysed. The results of the analysis indicated that the monetary variables such as interest rate, money supply affect the GDP in the short-term while they only effect inflation in the long-term.

The empirical studies supporting the New Keynesian approach are based on the studies of Romer and Romer (1989), Bernanke and Blinder (1992), Sims (1992) and Eichenbaum and Evans(1998) $)^{2}$ which were carried out for the US economy. The effects of monetary policy implementations on real economy were analysed in these studies. The results of the analysis show that the monetary instrument such as interest rate has an influence on real economy.

\section{Model Specification}

The New Keynesian model ${ }^{3}$ is given by the following:

$\pi_{t}=\kappa y_{t}+\beta E_{t} \pi_{t+1}+\omega_{t}$

$y_{t+1}-y_{t}=E_{t} \pi_{t+1}-\sigma\left(E_{t} i_{t}-i_{t}^{n}\right)$

$y_{t}=\phi_{\pi} \pi_{t}-\phi_{i} i_{t}$

The first equation captures the Phillips curve relationship. Where $\pi_{t}$ denotes inflation in period $t, E_{t}$ denotes the expectation conditional on all information available in period $\mathrm{t}, y_{t}$ which is an endogenous variable denotes the output gap, $\mathrm{i}_{\mathrm{t}}$ is interest rate used by policy authority (such as the policy rate of the central bank), and $\omega_{t}$ is a disturbance term. All measured as deviations from the

${ }^{1}$ See Cassola and Morana (2002), Wulandari (2012) for the Monetarist model.

${ }^{2}$ Some other studies about the New Keynesian model are Ma and Lee (2015), Baskand Proaño (2016).

${ }^{3}$ See Gali (2015) for more details about New Keynesian model. 
zero-inflation steady state. The output gap is defined as the deviation of output from potential output that is attainable under flexible prices. The variable $i_{t}^{n}$ denotes an exogenous process for the natural rate of interest. Ignoring the zero lower bound, and with standard assumptions on $\phi_{\pi}$ and $\phi_{i}$, there is a unique equilibrium with $\pi_{t}=y_{t}=0$ Equation 1 relates current inflation positively to expected future inflation and to the current output gap.

The first term reflects the forward-looking element of the Phillips curve that is consistent with the staggered feature of the Calvo (1983) framework, in which only a given fraction of firms adjust their prices in any given period. In this case, a higher expected future inflation induces firms to raise prices by more. The second term of the equation captures the extent to which monetary policy affects output level.

The second equation of the model is basically a forward-looking aggregate demand curve:

$$
y_{t}=E_{t} y_{t+1}-\beta\left(i_{t}-E_{t} \pi_{t+1}\right)+v_{t}
$$

where $i_{t}$ is the nominal interest rate and $v_{t}$ is a error term. According to In Equation 4 , there is a negative relationship between the output level and interest rate (Clarida, et al., 1999). Equation 4 can be derived from a standard Euler equation for consumption along with a relevant marketclearing condition. This expression incorporates the concept of consumption smoothing into the aggregate demand curve by relating the output gap positively to the expected future output gap and negatively to the ex-ante real interest rate, $i_{t}-E_{t} \pi_{t+1}$. As aggregate demand depends on consumer preferences and potential output is affected by technology shocks, the term $v_{t}$ is a disturbance consisting of both technology and preference shocks (Lee, 2009).

While the New Keynesian approach depends on the Philips Curve and total demand equation, the Monetarist approach depends on IS-LM model. This mechanism indicates the monetary policy directly affects the aggregate demand.

The equations of the model are listed below. All variables are expressed as natural logs:

$$
\begin{aligned}
& M_{t}^{S}=m_{0}+m_{1} k+m_{2} i_{t}+u_{m, t}+H_{t} \\
& M_{t}^{d}=\alpha_{0}-\alpha_{1} i_{t}+\alpha_{2} y_{t}+u_{M, t} \\
& M_{t}^{s}=M_{t}^{d} \\
& y_{t}=c_{0}-c_{1} i_{t}+c_{2} y_{t}+c_{3} M_{t}^{s}+u_{y, t} \quad 0<c_{2}<1,
\end{aligned}
$$

where $M^{s}=$ money supply, $H_{t}=$ supply of reserves, $m=$ money multiplier, $k=$ one minus the required reserve ratio (natural $\log <0$ ), $M^{d}=$ money demand, $i=$ interest 
The Effect of Interest Rate on Output Level and Inflation in Turkey: Evaluation of Monetarist and New Keynesian Perspective

rate, $y=$ real output, $u_{m}, u_{M}, u_{y}=$ normal independent zero mean random disturbances.

All coefficients are positive, and negative relationships are captured by a negative sign. If the monetary authority controls the monetary base, the endogenous variables are $M^{d}, i$ and $y$; the exogenous variables are $M^{s}, H$ and $k$. If it targets the interest rate, $H$ is endogenous and $i$ is exogenous.

Equation 5 and 6 determine the money supply and money demand respectively. Equation 7 is the money market clearing condition, while Equation 8 is the goods market clearing equation. The money multiplier is influenced by the required reserve ratio and the level of interest rates. It is also subject to random disturbances. Equation 8 has aggregate demand depending positively on the money supply, reflecting the operation of a Monetarist transmission channel.

The above system can be reduced to a two equation linear stochastic ISLM model. The reduced system is given by

$$
\begin{aligned}
& m_{0}+m_{1} k+m_{2} i_{t}+u_{m, t}+H_{t}=\alpha_{0}+\alpha_{1} k-\alpha_{2} i_{t}+\alpha_{3} y_{t}+u_{M, t} \\
& y_{t}=c_{0}-c_{1} i_{t}+c_{2} y_{t}+c_{3}\left[m_{0}+m_{1} k+m_{2} i_{t}+u_{m, t}+H_{t}\right]+u_{y, t .}
\end{aligned}
$$

Its solution depends on which instrument the monetary authority targets.In the Monetarist approach, monetary policy influences the price level. In the IS-LM model, since the price level is assumed as fixed, it is not located in the Equation 8. In the AD model, the price level is included in the model since it is endogenous. The total demand equation where the price level is endogenous will be as follows:

$$
y_{t}=c_{0}-c_{1} i_{t}+c_{2} y_{t}+c_{3} M_{t}^{s} / P_{t}+u_{y, t} \quad 0<c_{2}<1
$$

According to Equation 11, if partial derivative is taken on interest rate $\left(\frac{\partial y}{\partial i}\right)$, there is a negative relationhip between the output level and interest rate.

Equation 11 is reedited in order to see the effect of money supply on price level (Krause, 2006).

$$
\begin{aligned}
& M_{t}^{s} / P_{t}=y_{t}-c_{0}+c_{1} i_{t}-c_{2} y_{t}+u_{y, t} \\
& P_{t}=\frac{M_{t}^{s}}{y_{t}-c_{0}+c_{1} i_{t}-c_{2} y_{t}+u_{y, t}}
\end{aligned}
$$

According to Equation 13, if partial derivative is taken on interest rate $\left(\frac{\partial P}{\partial i}\right)$, there is a negative relationship between the interest rate and price level. So, 
this equation confirms the Monetarist approach that there is a negative relationship between the interest rate and inflation rate.

\section{Data and Methodology}

In this study, the mutual relationship among interest rate, output level andinflation rate in Turkey between the years of 2000:01-2015:12 were analyzed using time series methods. Firstly, the linearity of series was determined. Then, the order of stationary variables was proven. Then, a non-linear and linear ARDL test wereused to determine whether a short-term and long-term relationship existed among the variables in the models. Two models were used for ARDL tests. IPI and CPI were used as endegenous variables and IR is exegenous variable in both of the models. Three variables were employed in this study. IPI represented the industrial production index, CPI was the consumer prices index, and IR was Central Bank policy interest rate. Nominal value and monthly data related to these three variables were used in the study. Moreover, data were evaluated in logarithmic form. The related series were obtained from the electronic database of the International Monetary Fund (IMF). The data for this period were preferred as the data related to the study for Turkeywere available only for this period in the database.

\subsection{Fourier Unit Root Test}

Fourier Lagrange Multiplier $\left(\mathrm{F}_{\mathrm{LM}}\right)$ unit root test developed by Enders and Lee (2009) is used in this study. This test is a variant of the flexible fourier transform (Gallant, 1981) and is able to capturing the unknown nature of structural breaks without information about the numbers of breaks.

The $F_{L M}$ test, which is more powerful than Dickey-Fuller (DF) test, bases on the Lagrange Multiplier (LM) principle (Pascalau, 2010).

We use the following data generating process by following the paper of Enders and Lee (2009):

$$
\begin{aligned}
& y_{t}=\eta_{0}+\gamma_{t}+\alpha_{1} \sin \left(\frac{2 \pi k t}{T}\right)+\alpha_{2} \cos \left(\frac{2 \pi k t}{T}\right)+\varepsilon_{t} \\
& \varepsilon_{t}=\delta \varepsilon_{t-1}+u_{t}
\end{aligned}
$$

where $\mathrm{k}$ is the frequency prefered for the approach, $\alpha=\left[\alpha_{1}, \alpha_{2}\right]^{\prime}$ specifies the displacement and amplitude of the frequency component. An important feature of Equation 14 is that the standard linear specification emerges as a special case by setting $\alpha_{1}=\alpha_{2}=0$. If there is a structural break, at least one frequency component must be present in Equation 14. Here, if the null hypothesis $\alpha_{1}=\alpha_{2}=0$ is rejected, the series must have a nonlinear component. Enders and Lee (2009) employ this property of Equation 14 to improve a test that can have more power than the standard Bai and Perron (1998) test to detect breaks of an unknown form.

While $\delta=1$ under the null hypothesis of a unit root, $\delta<1$ under the alternative hypothesis of stationarity. Enders and Lee (2009) use the LM methodology by 
The Effect of Interest Rate on Output Level and Inflation in Turkey: Evaluation of Monetarist and New Keynesian Perspective

imposing the null restriction and estimating the following regression using first differences:

$\Delta y_{t}=\varphi_{0}+\varphi_{1} \Delta \sin \left(\frac{2 \pi k t}{T}\right)+\varphi_{2} \Delta \cos \left(\frac{2 \pi k t}{T}\right)+u_{t}$

The estimated coefficients, $\tilde{\varphi}_{0}, \tilde{\varphi}_{1}$ and $\tilde{\varphi}_{2}$ are used to construct the detrended series as follows:

$\tilde{S}_{t}=y_{t}-\tilde{\psi}-\tilde{\varphi}_{0} t-\sin \left(\frac{2 \pi k t}{T}\right)-\tilde{\varphi}_{2} \cos \left(\frac{2 \pi k t}{T}\right), \quad t=2, \ldots . ., T$

where $\tilde{\psi}=y_{1}-\tilde{\varphi}_{0}-\tilde{\varphi}_{1} \sin (2 \pi k t / T)-\tilde{\varphi}_{2} \cos (2 \pi k t / T) \cdot y_{1}$ is the fist observation of $y_{t}$.The detrended series is used in testing regression as follows:

$\Delta y_{t}=\lambda \tilde{S}_{t-1}+d_{0}+d_{1} \Delta \sin (2 \pi k t / T)+d_{2} \Delta \cos (2 \pi k t / T)+\varepsilon_{t}$

If $y_{t}$ has a unit root then $\lambda=0$ and the LM test statistic $\left(\tau_{L M}\right)$ is the t-test for the null hypothesis of $\lambda=0$. The innovation process $\varepsilon_{t}$ is assumed to satisfy Phillips and Perron (1988)'s conditions, which allow to serial correlation and heterogeneity. Equation 18 can be augmented with lag values of $\Delta \tilde{S}_{t-j}, j=1,2, \ldots ., p$, to get rid of the remaining serial correlation (Ng and Perron, 2001).

Enders and Lee (2009) derive the properties of the asymptotic distribution of the $\tau_{L M}$ statistic and show that the non-linear distribution of $\tau_{L M}$ depends on only the frequencyk. But is in variant to the magnitudes of $\alpha_{1}, \alpha_{2}, \eta_{0}$ and $\gamma$.They suggest determining the value of $\mathrm{k}$ using the integer values $1-5$ and choosing the $\mathrm{k}$ that minimizes the sum of squared residuals (SSR) from Equation 18.

If a nonlinear trend is present, a fourier unit root test with a nonlinear trend would be more powerful than the standart unit root test, so we use the following F-statistic to test the existence of a nonlinear trend:

$$
F(k)=\frac{\left(S S R_{0}-S S R_{1}(k) / 2\right)}{S S R_{1}(k) /(T-q)}
$$

where $S S R_{1}(k)$ shows the sum of squared residuals from Equation 17, q shows the number of regressors, and $S S R_{0}$ is the SSR from Equation 17 without trigonometric terms. Enders and Lee (2011) tabulated the relevant critical values are in their paper, since the distribution of this statistic is not standard. If the null of linear trend is rejected, then $\mathrm{F}_{L M}$ unit root test will be used; otherwise the standard 
unit root tests without a nonlinear trend will be employed (Yilanc1 and Tunali, 2014).

\subsection{Non-Lineer ARDL Model}

The non-linear ARDL (NARDL) approach for cointegration testing has several interesting characteristics. First, it performs better on small samples compared to alternative multivariate cointegration procedures. Second, it permits to test both the linear and nonlinear cointegration. Third, it distinguishes between the short- and long-run effects from the independent variable to the dependent variable. Even if all the three previous facts could also be tested within a nonlinear threshold Vector Error Correction Model (VECM) or by smooth transition model, these models may suffer from the convergence problem due to the proliferation of the number of parameters, which is not the case with the NARDL model. Fourth, it does not require the restrictive assumption that all series are integrated of the same order allowing for the inclusion of both I(0) and I(1), the NARDL model relaxes this restriction and allows combining data series having different integration orders. Following the above arguments, the NARDL model developed by Shin, Yu, and Greenwood-Nimmo (2014) is chosen for our analysis. The standard linear ARDL (p,q) cointegration model developed by Pesaran, et al., (2001) with two time series $y_{t}$ and $x_{t}(\mathrm{t}=1,2, \ldots, \mathrm{T})$ is as follows:

$\Delta y_{t}=\alpha_{0}+\rho y_{t-1}+\theta x_{t-1}+\gamma z_{t}+\sum_{i=1}^{p=1} \alpha_{i} \Delta y_{t-j}+\sum_{i=0}^{q=1} \pi_{i} \Delta x_{t-i} e_{t}$

where $z_{t}$ is a vector of deterministic terms and $e_{t}$ is an iid stochastic process. Under the null hypothesis of no cointegration, the coefficients of the lagged levels of $y_{t}$ and $x_{t}$ in Equation (20) are jointly zero $(\rho=\theta=0)$ Pesaranet al., (2001) showed that the assumption of no cointegration can be tested either by means of a modified $\mathrm{F}_{P S S}$ test or by means of a $\mathrm{W}_{P S S}$ test. Null hypothesis of no cointegration can be also assessed by means of $\mathrm{t}_{B D M}$ test. If null hypothesis of no cointegration is accepted, linear methods can be used. On the other hand null hypothesis of no cointegration is rejected, the non-linear methods can be employed (Pesaran, et al., 2001).

The combination of stochastic regressors in the standard ARDL approach is linear, implying linear adjustments in the long and the short-run. To account for nonlinearity, Shin et al. (2014) introduced the NARDL model in which uses the decomposition of the exogenous variable $\mathrm{x}_{\mathrm{t}}$ into its positive $x_{t}^{+}$and negative $x_{t}^{-}$ partial sums for increases and decreases such as:

$x_{t}^{+}=\sum_{i=1}^{t} \Delta x_{i}^{+}=\sum_{i=1}^{t} \max \left(\Delta x_{i,}, 0\right)$ 
The Effect of Interest Rate on Output Level and Inflation in Turkey: Evaluation of Monetarist and New Keynesian Perspective

$\overline{x_{t}^{-}}=\sum_{i=1}^{t} \Delta x_{i}^{-}=\sum_{i=1}^{t} \min \left(\Delta x_{i,}, 0\right)$

NARDL model, the null hypothesis of no coingration $\left(\rho=\theta^{+}=\theta^{-}=0\right)$ can be tested using the $\mathrm{F}_{P S S}, \mathrm{~W}_{P S S}$ and the $\mathrm{t}_{B D M}$ statistic like ARDL. After the linearity is tested by $\mathrm{F}_{P S S}, \mathrm{~W}_{P S S}$ and $\mathrm{t}_{B D M}$ tests, the non-linear long and short run relationship can be analysed. The non-linear long-run equilibrium relationship can be expressed as:

$y_{t}=\beta^{+} x_{t}^{+}+\beta^{-} x_{t}^{-}+u_{t}$

where $\beta^{+}$and $\beta^{-}$are the non-linear long-run parameters associated with positive and negative changes in $\mathrm{x}_{\mathrm{t}}$, respectively. Shin et al., (2014) showed that by combining (23) with the $\operatorname{ARDL}(p, q)$ model we obtain the NARDL(p,q) model as:

$$
\begin{aligned}
\Delta y_{t}= & \alpha_{0}+\rho y_{t-1}+\theta^{+} x_{t-1}^{+}+\theta^{-} x_{t-1}^{-}+\sum_{i=1}^{p-1} \alpha_{i} \Delta y_{t-i} \\
& +\sum_{i=0}^{q-1}\left(\pi_{i}^{+} \Delta x_{t-i}^{+}+\pi_{i}^{-} \Delta x_{t-i}^{-}\right)+e_{t}
\end{aligned}
$$

where $\theta^{+}=-\rho / \beta^{+}$and $\theta^{-}=-\rho / \beta^{-}$. The long-run linearity can be tested by using a Wald test of the null hypothesis that $\theta^{+}=\theta^{-}$. The long-run coefficients with respect to the negative and positive changes of the independent variables can be computed as $\beta^{+}=-\theta_{x}^{+} / \theta_{y}$ and $\beta^{-}=-\theta_{x}^{-} / \theta_{y}$. These coefficients measure the relationship between $\mathrm{x}$ and $\mathrm{y}$ at the long-run equilibrium. The short-run adjustment of $y_{t}$ to a positive or negative variation of $x_{t}$ is captured by the parameters $\pi^{+}$and $\pi^{-}$, respectively (Shin, et al.,2014). The short run symmetry can be tested by using a standard Wald test of the null hypothesis that $\pi_{i}^{+}=\pi_{i}^{-}$for all $\mathrm{j}=1, \ldots \mathrm{q}-1$.

Finally, non-linearity in the model can be observed either in the long-run, in the short-run or in both. In that case, the non-linear responses of the dependent variable to positive and negative variations of the independent variable are respectively captured by the positive and negative dynamic multipliers associated with unit changes in $x^{+}$and $x^{-}$as follows:

$$
m_{h}^{+}=\sum_{j=1}^{h} \frac{\partial y_{t+j}}{\partial x_{t}^{+}} \text {and } m_{h}^{-}=\sum_{j=1}^{h} \frac{\partial y_{t+j}}{\partial x_{t}^{-}} \text {with } \mathrm{h}=0,1 \text {, }
$$


where $h \rightarrow \infty, m_{h}^{+} \rightarrow \beta^{+}$and $m_{h}^{-} \rightarrow \beta^{-}$by construction (with $\beta^{+}=-\rho_{x}^{+} / \rho_{y}$ and $\beta^{-}=-\rho_{x}^{-} / \rho_{y}$ are the long-run coefficients explained above).Under the NARDL framework, 2 models are applied in this paper. These are as follows:

$$
\begin{aligned}
& \Delta i p i_{t}=\mu+\rho_{y} i p i_{t-1}+\theta_{x}^{+} i r_{t-1}^{+}+\theta_{x}^{-} i r_{t-1}^{-}+\sum_{j=1}^{p-1} \alpha_{i} \Delta i p i_{t-i}+\sum_{j=0}^{q-1} \beta_{j}^{+} \Delta i r_{t-j}^{+}+\sum_{j=0}^{q-1} \beta_{j}^{-} \Delta i r_{t-j}^{-}+\varepsilon_{t} \\
& \Delta c p i_{t}=\mu+\rho_{y} c p i_{t-1}+\rho_{x}^{+} i i_{t-1}^{+}+\rho_{x}^{-} i r_{t-1}^{-}+\sum_{j=1}^{p-1} \alpha_{i} \Delta c p i_{t-i}+\sum_{j=0}^{q-1} \beta_{j}^{+} \Delta i r_{t-j}^{+}+\sum_{j=0}^{q-1} \beta_{j}^{-} \Delta i r_{t-j}^{-}+\varepsilon_{t}
\end{aligned}
$$

In Equation 26, the relationship between the output level and interest rate is analysed. If there is a relationship between these variables in the short-run, it can be concluded that New Keynesian approach is valid. The relationship between the inflation and interest rate is analysed in Equation 27. If there is a relationship between these variables in the short and long-run, Monetarist approach valid.

\section{Empirical Findings}

Table 1 shows the results of the $\mathrm{F}_{\mathrm{LM}}$ unit root test. Column 2 of table 1 indicates the best frequency, selected using a grid search to find the minimum SSR estimating Equation 18 for each integer $\mathrm{k}=1 \ldots . .5$. The results show that a single frequency works best for the whole series. The $\mathrm{f}(k)$ statistics in the fourth column of the table indicate that trigonometric terms should be included in the estimated models. $F_{L M}$ unit root test statistics in column 5 indicates the result of fourier unit root test. DF unit root test statistics in column 6 shows the result of Dickey Fuller unit root test.

\section{Table 1. Results of fourier unit root tests}

\begin{tabular}{lcllll}
\hline Variables & $\mathrm{SSR}_{1}$ & Freq & $\mathrm{F}(\mathrm{k})$ & $\mathrm{F}_{\mathrm{LM}}$ & $\mathrm{DF}$ \\
\hline cpi & 47.80123 & 1 & $13.45^{* * *}$ & $7.8(9)$ & \\
ipi & 50.86757 & 1 & 3.388 & 5.87 & $1.457(5)$ \\
ir & 0.7992 & 1 & $10.97^{* * *}$ & 79.44 & \\
& & & & $(7)^{* * *}$ & \\
\hline
\end{tabular}

Note: Numbers in paranthesis indicate the optimal lag length. $* * *$ indicates the significance level at $1 \%$.

As a result of the $\mathrm{f}(k)$ test, it was determined that the ipi series have linear where cpi and ir series have non-linear processes. The reason for the non-linearity in the interest rates may exist due to the transaction costs. Moreover, adverse selection and moral hazard problems caused by asymmetric information in financial markets cause banks to go to credit rationing. These costs and barriers can cause non-linearities in the interest rates. Furthermore, price and wage stickiness, 
The Effect of Interest Rate on Output Level and Inflation in Turkey: Evaluation of Monetarist and New Keynesian Perspective

and monopolistic competition structure of markets can be raised to non-linearities within inflation-output relationship.

We prefer the $F_{L M}$ test since a nonlinear trend is present, show that the cpi series includes unit root and ir series is series is stationary. We use standard DF unit root test since standard unit root tests are more powerful than Fourier tests as stated by Enders and Lee (2011) when linear trend is present. The results of DF unit root test cannot reject the null of a unit root for ipi.

Due to the difference in the series, it is necessary to determine whether there is a different structure in the model. For this reason; the use of NARDL method makes it possible to determine whether there is a non-linear relationship in the model in short and long-term. For the NARDL test, just like it is in the ARDL model, firstly it is analysed to find out whether there is co-integration or not. The table 2 shows the non-linear co-integration test results.

Two models are used in order to evaluate the relationship between inflation and interest in terms of the New Keynesian and the Monetarist approachs. In the first model, industry production index is used as a dependent variable while the interest rate is used as an independent variable. In the second model, interest rate is used as independent variable while consumer price index is used as a dependent variable.

According to non-linear co-integration results in Table 2, the $\mathrm{F}_{P S S}, \mathrm{~W}_{P S S}$ and the $\mathrm{t}_{B D M}$ statistics cannot reject the null hypothesis for the first model. Besides, the $\mathrm{F}_{\mathrm{PSS}}$ and $\mathrm{W}_{P S S}$ statistics reject the null hypothesis for the second model. According to this, while there is a linear relationship in the first model, there is a partial non-linear relationship in the second model.

Table 2. Bound testing for non-linear cointegration

\begin{tabular}{|c|c|c|}
\hline \multicolumn{3}{|c|}{ Direction of relationship } \\
\hline Statistics & ir to ipi & ir to cpi \\
\hline FPSS $_{\text {PS }}$ & 1.1835 & $7.2563 * * *$ \\
\hline $\mathrm{W}_{\mathrm{PSS}}$ & 1.245 & $7.3145^{* * * *}$ \\
\hline $\mathrm{t}_{\mathrm{BDM}}$ & -1.733 & -2.0849 \\
\hline $\begin{array}{l}\text { Note: for } \mathrm{k}=1 \\
\text { and the } \mathrm{t}_{\mathrm{BDM}} \\
-3.22) \text {, respec }\end{array}$ & $\begin{array}{l}\text { the } 1 \%(5 \%) \text { level of } \mathrm{s} \\
\text { s are } 6.84 \text { to } 7.84(4.94 \\
\text { The critical values have }\end{array}$ & $\begin{array}{l}\text { values (bounds) for the } \mathrm{F}_{\mathrm{PSS}} \text {, the } \mathrm{W}_{\mathrm{PSS}} \\
\text { to11.52) and }-3.43 \text { to }-3.82(-2.86 \text { to } \\
\text { al. (2001).*** and } * * \text { denote rejection }\end{array}$ \\
\hline
\end{tabular}

Table 3 shows the non-linearity test results. The Wald test cannot reject the null hypothesis for the first model. Therefore, the relationship between the variables in the model is linear. Thereby, it is more appropriate to use a linear method for the estimation of the model. Moreover, while the Wald test cannot reject the null hypothesis in the long term, it rejects it in the short term. Thus, the 
short-term relationship has a non-linear structure for the second model while the long-term relationship has a linear structure.

Table 3. Long and short run linearity test

\begin{tabular}{lll}
\hline & \multicolumn{1}{l}{ ir to ipi } & ir to cpi \\
\hline Ntatistics & NARDL model with LR & NARDL model with LR and \\
& $\begin{array}{l}\text { and } \\
\text { SR non-linearity } \\
\text { SR non-linearity }\end{array}$ \\
\hline $\mathrm{W}_{\mathrm{LR}}$ & $.05528(0.814)$ & $.8707(0.352)$ \\
$\mathrm{W}_{\mathrm{SR}}$ & $.02104(0.888)$ & $2.969(0.087)^{*}$ \\
\hline $\begin{array}{l}\text { Note: } \mathrm{W}_{\mathrm{LR}} \text { refers to theWald test for the null of long-run linearity. } \mathrm{W}_{\mathrm{SR}} \text { refers to theWald test for the null of the } \\
\text { additive (weak-form) linearity. } p \text {-values are displayed in parentheses. } \\
\text { of linearity at the } 1 \% \text { level. }\end{array}$
\end{tabular}

Table 4 presents the parameter estimates of the models applied above. It also presents (at its lower part) diagnostic tests which are quite satisfactory. Although there are not any problem about serial correlation and heteroscedasticity for the first model, the estimate of the long-run coefficients $\beta^{+}$and $\beta^{-}$are insignificant. Moreover, short run relationship is also insignificant. Serial correlation and heteroscedasticity problem are also absent for the second model. The estimate of the long-run coefficients $\beta^{+}$and $\beta^{-}$are insignificant. On the other hand, short run relationship are significant at any different lag level for the second model. The lags of interest rate are significant, suggesting that the monetary policy affects with time lag. For example, the coefficients of $\Delta i r_{t-1}^{+}(0.0905)$ and $\Delta i r_{t-2}^{+}$ $(0.1313)$ are significant and positive signs. $\Delta i r_{t-4}^{+}$is also statistically insignificant. Furthermore, the coefficients of $\Delta i r_{t-1}^{-}(-0.0985)$ and $\Delta i r_{t-2}^{-}(-0.0962)$ are significant and nagative. According to these results, it is understood that the monetary policy affects the inflation with time lag, and this effect gets weaker in the long term.

Table 4. NARDL estimation results ${ }^{4}$

${ }^{4}$ The estimations and tests were conducted using a program code written in STATA which was produced by M. Sunder and retrieved from Matthew Greenwood-Nimmo's webpage. 
The Effect of Interest Rate on Output Level and Inflation in Turkey: Evaluation of Monetarist and New Keynesian Perspective

\begin{tabular}{|c|c|c|c|c|c|}
\hline \multicolumn{3}{|l|}{ ir to ipi } & \multicolumn{3}{|l|}{ ir to cpi } \\
\hline \multicolumn{3}{|c|}{ NARDL model with SR linearity } & \multicolumn{3}{|c|}{ NARDL model with LR and SR non-linearity } \\
\hline Variable & Coefficient & Standard error & Variable & Coefficient & Standard error \\
\hline constant & -.114 & .0540 & constant & .175 & .0880 \\
\hline$i p i_{t-1}$ & -.1251 & .0403 & $c p i_{t-1}$ & -.0165 & .0194 \\
\hline$i r_{t-1}^{+}$ & -.0124 & .0072 & $i r_{t-1}^{+}$ & .0134 & .0256 \\
\hline$i r_{t-1}^{-}$ & -0197 & .0063 & $i r_{t-1}^{-}$ & .0726 & .0474 \\
\hline$\Delta i p i_{t-1}$ & -.6220 & .0590 & $\Delta c p i_{t-2}$ & .0251 & .0814 \\
\hline$\Delta i p i_{t-4}$ & .0463 & .0919 & $\Delta c p i_{t-4}$ & -.140 & .0852 \\
\hline$\Delta i p i_{t-8}$ & .1552 & .0899 & $\Delta c p i_{t-8}$ & .0672 & .0791 \\
\hline$\Delta i p i_{t-11}$ & -.282 & .0750 & $\Delta c p i_{t-11}$ & -.0455 & .0792 \\
\hline$\Delta i r_{t}^{+}$ & -.0015 & .0203 & $\Delta i r_{t}^{+}$ & .0144 & .0637 \\
\hline$\Delta i r_{t-1}^{+}$ & -.0446 & .0323 & $\Delta i r_{t-1}^{+}$ & $.0905 * *$ & .0399 \\
\hline$\Delta i r_{t-2}^{+}$ & -.0018 & .02099 & $\Delta i r_{t-2}^{+}$ & $.1313 * *$ & .0554 \\
\hline$\Delta i r_{t-3}^{+}$ & -.0064 & .0215 & $\Delta i r_{t-3}^{+}$ & $.1064 *$ & .0564 \\
\hline$\Delta i r_{t-4}^{+}$ & .0097 & .0207 & $\Delta i r_{t-4}^{+}$ & -.0762 & .0471 \\
\hline$\Delta i r_{t}^{-}$ & -.0010 & .0251 & $\Delta i r_{t}^{-}$ & -.0987 & .0678 \\
\hline$\Delta i r_{t=}^{-}$ & .0023 & .0274 & $\Delta i r^{-}$ & $-.0985^{* * *}$ & .0521 \\
\hline$\Delta i r_{t-2}^{-}$ & -.0227 & .0289 & $\begin{array}{l}\Delta t_{t-1} \\
\Delta i r_{t-2}^{-}\end{array}$ & $-.0962 *$ & .0543 \\
\hline \multicolumn{3}{|c|}{ Long-run non-lineareffect of interest } & \multicolumn{3}{|c|}{ Long-run non-lineareffect of interest rate } \\
\hline$\beta_{i r}^{+}$ & $-0.100(0.118)$ & & $\beta_{c p i}^{+}$ & $-0.690(0.172$ & \\
\hline$\beta_{i r}^{-}$ & $0.158(0.150)$ & & $\beta_{c p i}^{-}$ & $-0.455(0.140$ & \\
\hline \multicolumn{2}{|c|}{ Statistics and diagnostics } & \multicolumn{2}{|c|}{ Statistics and diagnostics } & & \\
\hline $\mathrm{R}^{2}$ & 0.583 & & & 0.358 & \\
\hline $\mathrm{SC}$ & $1.825(0.1$ & & $\mathrm{C}$ & $0.147(0.93$ & \\
\hline $\mathrm{ARCH}$ & $2.652(0.1$ & & $\mathrm{RCH}$ & $2.708(0.10$ & \\
\hline
\end{tabular}


Note: The superscripts “+” and "-" denote positive and negative partial sums, respectively. $\beta^{+}$and $\beta^{-}$are the estimated long-runnon-linearity coefficients associated with positive and negative changes, respectively, SC and ARCH denote LM tests for serial correlation and conditional heteroscedasticity, respectively.p-values are displayed in parentheses. $* *$ and $*$ denote significance at the 5 and $10 \%$ levels, respectively.

Figure1 presents the dynamic multipliers for the monetary policy. It was observed that output level respond at the same rate, in the short-run and long run, to interest rate increases and decreases. The behavior of the dynamic multiplier is consistent with short-run and long-run linear.

Figure 2also presents the dynamic multipliers for the monetary policy. We observe that inflation rate respond at the different rate, in the short-run, to inflation rate increases and decreases. Moreover, the inflation regimes, such as high and low inflation, affect inflation differently. This also points to the threshold effect. The behavior of the dynamic multiplier is consistent with short-run non-linearity and long-run linearity.Although the first model is linear both in the short and long-term and the second model has a non-linear structure in the short-term and has a linear structure in the long term, it is not possible to reach an exact conclusion with the NARDL results presented in Table 4. Therefore, linear ARDL method was used for the estimation of these methods.

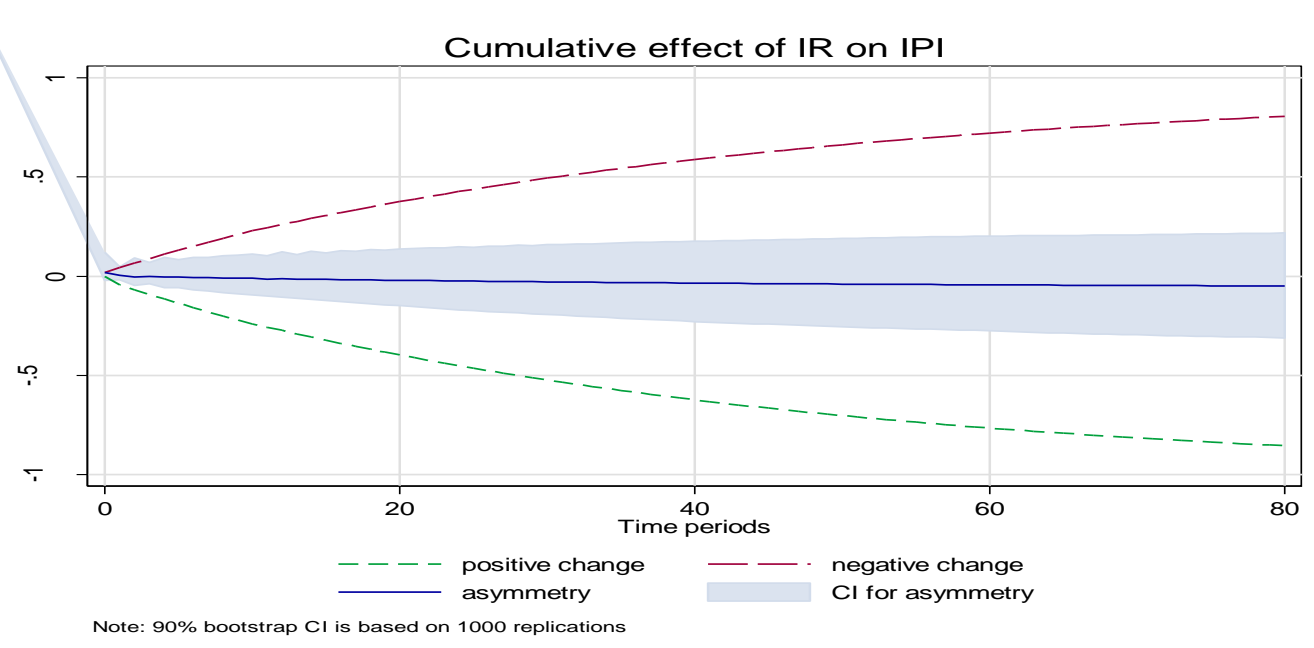

Figure 1. Dynamic multipliers. Interest rate to output level. 
The Effect of Interest Rate on Output Level and Inflation in Turkey: Evaluation of Monetarist and New Keynesian Perspective

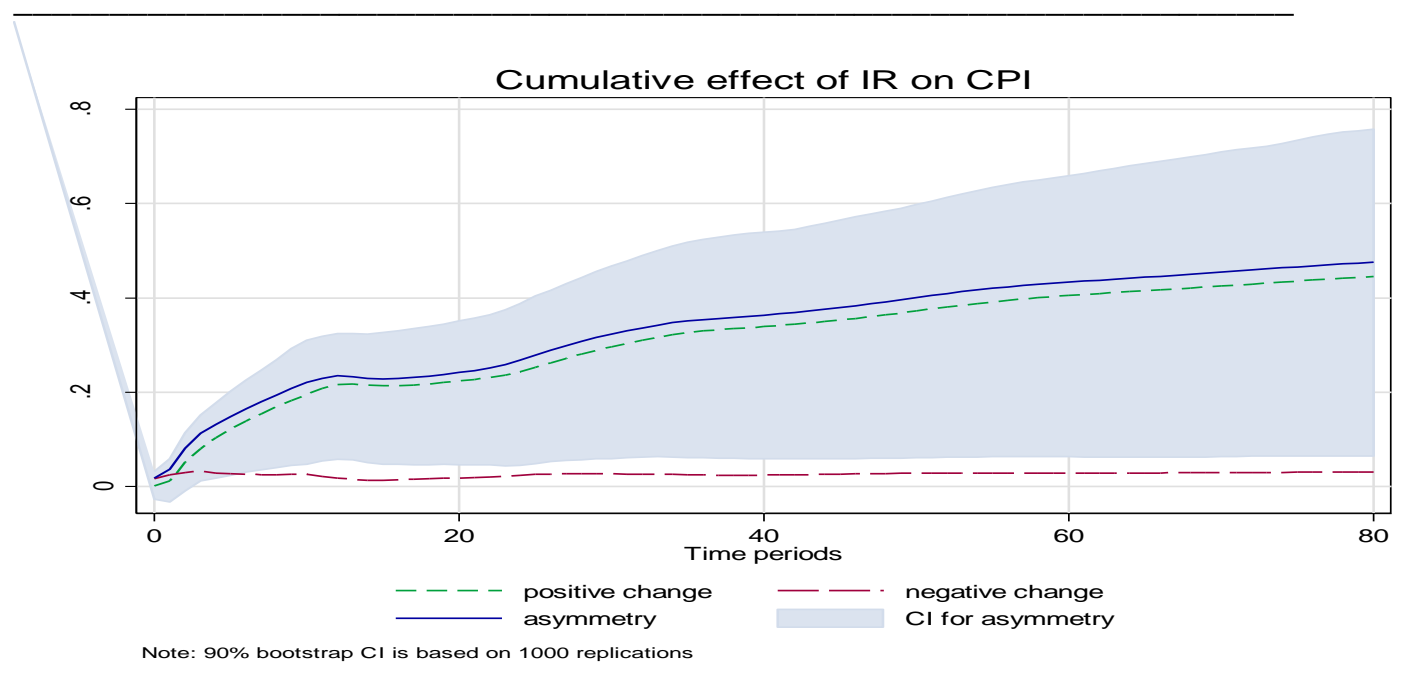

Figure 2. Dynamic multipliers. Interest rate to consumer price index.

Table 5 shows the ARDL results. There is an insignificant relationship in the short term and long term for the first model. Therefore, the monetary policy does not affect the level of output, both in the short and long term.

The second model is statistically significant both in the short and long term. The error term co-efficient is positive and between 0 and 1 . This result indicates that the deviations occurred in the equlibrium level in the short term cannot be stabilized in the long term and it will be hard to achieve the equlibrium level. The interest rate is a negative sign for both short and long term. This situation indicates that the increase in the interest rate will reduce the inflation rate both in the short and long term. However, interest rates affect inflation at different lags. For example, the coefficients of $\Delta \ln i r_{t-1}(-0.02326)$ and $\ln i r_{t-1}(-0.0128)$ are statistically significant and negative.This conclusion indicates that monetary policy affects the inflation with time lag.

Table 5.Estimate of the linear ARDL model

\begin{tabular}{|c|c|c|c|}
\hline \multicolumn{2}{|l|}{ ir to ipi } & \multicolumn{2}{|l|}{ ir to cpi } \\
\hline \multicolumn{2}{|c|}{ Panel A: Short run estimates } & \multicolumn{2}{|c|}{ Panel A: Short run estimates } \\
\hline coefficient & st.error & coefficient & st.error \\
\hline$\Delta \ln i p i_{t-1}$ & 0.549 & $\Delta \ln c p i_{t-1}{ }_{0.5774^{* * * *}}$ & 0.0525 \\
\hline
\end{tabular}


Yusuf Ekrem Akbas, Canan Sancar

\begin{tabular}{|c|c|c|c|c|}
\hline$\Delta i r_{-0.0138}$ & 0136 & $\Delta \ln i r_{-0.03438}$ & \multicolumn{2}{|l|}{0.0490} \\
\hline$\Delta i r_{t-1}{ }_{-0.0460}$ & 0.125 & $\Delta \ln i r_{t-1}$ & $-0.023 * * * *$ & 0.0041 \\
\hline$-0.3111 * *$ & 0.1425 & \multicolumn{2}{|c|}{0.04790 .1135} & \\
\hline \multicolumn{2}{|c|}{ Panel B: Long run estimates } & \multicolumn{3}{|c|}{ Panel B: Long run estimates } \\
\hline $\ln$ ipi $_{t-1}{ }_{0.31159}$ & 0.570 & $\ln c p i_{t-1}{ }_{1.5032 * * *}$ & \multicolumn{2}{|c|}{0.05204} \\
\hline $\ln i p i_{t-2} \quad 0.6038$ & 0.546 & $\ln c p i_{t-2}-0.55139^{* * *}$ & \multicolumn{2}{|c|}{0.05083} \\
\hline $\ln i r \quad-0.0027$ & 0.012 & $\ln i r_{-0.01124^{* *}}$ & \multicolumn{2}{|l|}{.00391} \\
\hline $\ln i r_{t-1} \quad-0.04396$ & 0.126 & $\ln i r_{t-1}{ }_{-0.0128^{* * * *}}$ & \multicolumn{2}{|c|}{0.00352} \\
\hline $\ln i r_{t-2} \quad-0.0227$ & 0.028 & $\ln i r_{t-2} \quad 0.02413^{* * *}$ & \multicolumn{2}{|c|}{0.00395} \\
\hline constant & 0.143 & constant & \multicolumn{2}{|c|}{0.0976814223} \\
\hline \multicolumn{2}{|c|}{ Panel C: diagnostic tests } & \multicolumn{3}{|c|}{ Panel C: diagnostic tests } \\
\hline \multicolumn{2}{|c|}{$F E E C M_{t-1} L M$ Adj.R $R^{2}$} & \multicolumn{3}{|c|}{$F E C M_{t-1} L M$ Adj.R $R^{2}$} \\
\hline $\begin{array}{l}-0.07342 \\
(-1.32)\end{array}$ & 6.264 & $\begin{array}{ll}21.87^{* * * *} & \begin{array}{l}.8182^{* * * *} \\
(4.97)\end{array}\end{array}$ & 0.621 & 0.56 \\
\hline
\end{tabular}

Note: Absolute t-ratios are in parentheses. $* * *$ and $* *$ indicate the $1 \%$ and $5 \%$ significance level respectively.

The results of $1^{\text {st }}$ and $2^{\text {nd }}$ model indicate that rather than New Keynesian approach, Monetarist approach is valid in Turkey after 2000.According to New Keynesian approach that emphasizes the fact that the interest rate is effective on the output level, a decrease in the interest rate will also decrease the investment costs. This will lead to the increase in the total supply by increasing the investment spending. The increase in the total supply will decrease unemployment and alleviate the inflationist stresses by surplus outputs. However, this result is not valid for this study because there is not a strong relationship between the interest rate and the output rate. The reason for this situation can be that the private sector in Turkey prefers borrowings from foreign banks rather than borrowings from national ones. Foreign interest rates are lower than the domestic interest rates. Moreover, local firms can easily borrow from abroad and therefore, firms mostly prefer borrowings from abroad.

Determining the relationship between the interest rate and the output level depends on the share of financing expenses within the costs of the firms. If the share of financing expense within firms' cost is not high, it is not expected that the 
The Effect of Interest Rate on Output Level and Inflation in Turkey: Evaluation of Monetarist and New Keynesian Perspective

decrease in the interest rate will increase the investment by lowering the firm's costs. In other words, the interest channel is not effective in that case. In such a case, in order to alleviate the inflationist pressures it is more effective to increase the interest rates as it will decrease the total demand. As it is shown in Appendix 1, in Turkey the share of the financing expenses including interest expenses among total expenses was $2.2 \%$ in 2013. The share of the interest expenses within the cost items of the firms is very low. Therefore, decreasing the interest rate might create a minor effect on prices. According to this, it is not possible to prevent the cost increase by decreasing the interest on the contrary such a decrease may lead to rise of the prices due to the increased demand.

In the study, one of the reasons why interest rates positively and significantly affect inflation was that the CPI is higher than the PPI. It is very crucial to determine the source of the inflation to examine the relationship between the interest rate and inflation rate, if the cost inflation is more powerful than the demand inflation, it can be said that decreasing the interest rate is effective in fighting against the inflation. But, if the demand inflation is more powerful, it is more effective to increase the interest rate to fight against inflation. Appendix 2 shows that while the increase in Producer Price Index (PPI) drops in, the increase in the Consumer Price Index (CPI) continues to rise. The producer price index represents the costs in general and the consumer price index represents the demand. Despite the fact that there is a drop in the increase of PPI, namely costs; continuous rise in CPI, that indicates the demand, shows that demand inflation is more dominant in Turkey in that period.

\section{Conclusion and Policy Recommendations}

In this study, the relationship between inflation-interest rate and output level was evaluated in terms of the Monetarist and the New Keynesian approach for the period between 2000M1 and 2015M12 in Turkey. Also, it was aimed to clarify the discrepancy between the government and CBRT by determining the direction of the relationship between interest rate and inflation rate. These relationships among the variables were analysed by linear and non-linear methods.

Results of the analysis indicated that rather than the New Keynesian approach, the Monetarist approach is valid in Turkey for the period after 2000. Moreover, the data shows that the volatility of both inflation and interest rate has decreased over the period 2000M1-2015M12. The volatility of interest rate (policy rate) decreased over this period. This suggests that the central bank has successfully implemented the inflation targeting policy in Turkey. Also it was found out that while the interest rate is effective on the inflation rate, it is not as much effective on the output level. Therefore, it is more appropriate for the Central Bank of the Republic of Turkey (CBRT) to prefer the inflation rate to output level as a final target. Thus, in the debate between the Turkish Government and the Central bank of the Republic of Turkey on the issue of the interest rate, consideration of the CBRT is more appropriate. The CBRT should fight against the inflation at first. Therefore, it is expected from the CBRT to increase the interest 
rates in order to alleviate the inflationist pressures. After the alleviation of the inflationist pressures, the focus should be directed to the production level. If CBRT focus on price stability, production level will be positively effected by low inflation since price stability decreases the uncertanities.

The monetary policy executer's providing price stability has a positive effect on the expectations and this situation reduces the uncertainty. The reduction of uncertainty encourages investors to make investments. Therefore, obtaining the price stability affects the output level in a positive way. The CBRT, the monetary authority, should apply the strategies supported by the public opinion in order to implement a successful policy. Namely, the CBRT should have high credibility in order to be successful in the implemented policies. The high credibility of the central banks depends on the increased independence of the central banks and the increased accountability with transparency. For this reason, the political pressure should be reduced in order to make the CBRT more independent and the CBRT should make its own decisions by taking the market conditions into account. As a result of the pressure made by the political authority on the decisions of the CBRT, it will be difficult to reach the final target, which is, price stability. This condition will have a negative effect on the output level by increasing the uncertainty.For all these reasons, the CBRT should focus on price stability. Government support is also needed to achieve this goal. While the CBRT is focusing on price stability, the government should not increase public expenditures and should not make compromises inthe fiscal discipline. In this way, it will be easier to maintain price stability.

\section{REFERENCES}

[1]Bai, J., Perron, P. (1998), Estimating and Testing Linear Models with Multiple Structural Changes.Econometrica, 66, 47-78;

[2]Bask, M.,Proaño, C.R. (2016), Optimal Monetary Policy Underlearning and Structural Uncertainty in a New Keynesian Model with a Cost Channel and

Inflation Inertia. Journal of Economic Dynamics \& Control, (69), 112-126; [3]Bernanke, B.S.,Blinder, A.S. (1992), The Federal Funds Rate and the Channels of Monetary Transmission.The American Economic Review, Vol. 82, No. 4. pp. 901-921;

[4]Calvo, G. (1983), Staggered Prices in a Utility Maximizing Framework. Journal of Monetary Economics, 12 (3), 383-398;

[5]Cassola, N., Morana, C.(2002), Monetary Policy and the Stock Market in the Euro Area. ECB Working Paper No. 119;

[6]Clarida, R.,Galı', J., Gertler, M.(1999), The Science of Monetary Policy: A New Keynesian Perspective. Journal of Economic Literature. 37, 1661-1707; [7]Enders, W.,Lee, J.(2009), The Flexible Fourier Form and Testing for Unit Roots: An Example of the Term Structure of Interest Rates; Working Paper, 
The Effect of Interest Rate on Output Level and Inflation in Turkey: Evaluation of Monetarist and New Keynesian Perspective

Department of Economics. Finance \& Legal Studies, University of Alabama, Tuscaloosa, AL, USA;

[8]Friedman, M., and Schwartz, A.J. (1963), A Monetary History of the United States, 1867-1960. Princeton: Princeton University Press;

[9]Gallant, R.A.(1981), On the Basis in Flexible Functional Form and an Essentially Unbiased Form: The flexible Fourier Form. Journal of Econometrics, (15): 211-353;

[10]Gali, J. (2015), Monetary Policy, Inflation, and the Business Cycle: An Introduction to the New Keynesian Framework and Its Applications. Princeton University Press;

[11]Krause, S. (2006), Optimal Monetary Policy and the Equivalency between the One-Period AD-AS Model and the Forward-Looking New Keynesian Model.Applied Economic Letters, (9), 541-544;

[12]Lee, J. (2009), Evaluating Monetary Policy of the Euro Area with CrossCountry Heterogeneity: Evidence from a New Keynesian Model.Economic Systems, (33), 325-343;

[13]Ma, Y., Li, S. (2015), Bayesian Estimation of China's Monetary Policy

Transparency: A New Keynesian Approach. Economic Modelling, (45), 236-248. [14]Ng, S.,Perron, P. (2001), Lag Length Selection and the Construction of Unit Root Tests with Good Size and Power. Econometrica, 69, 1519-1554;

[15]Smets, F.,Wouters R. (2007), Shocks and Frictions in US Business Cycles:

A Bayesian DSGE Approach. American Economic Review, 97, 586-606;

[16]Pascalau, R. (2010), Unit Root Tests with Smooth Breaks: An Application to the Nelson-Plosser Data Set.Applied Economics Letters, 17, 565-570;

[17]Phillips, P.C.B.,Perron, P.(1988), Testing for Unit Roots in Time Series Regression. Biometrika, 75, 335-346;

[18]Pesaran, M.H., Shin, Y., Smith, R.J. (2001), Bounds Testing Approaches to the Analysis of Level Relationships. Journal of Applied Econometrics 16 (3), 289-326;

[19]Romer, C.D.,Romer, D.H. (1989), Does Monetary Policy Matter? A New Test in the Spirit of Friedman and Schwartz. In Olivier J. Blanchard and Stanley Fischer, eds.,NBERMacroeconomics Annual 1989. Cambridge, MA: MIT Press, pp. 121-70;

[20]Shin, Y., Yu, B.C., Greenwood-Nimmo, M. (2014). Modelling Asymmetric Cointegration And Dynamic Multipliers in a Nonlinear ARDL Framework. In: Sickels, R., Horrace, W. (Eds.), Festschrift in Honor of Peter Schmidt:

Econometric Methods and Applications. Springer, New York, NY, pp. 281-314;

[21]Sims, C.A. (1992), Interpreting the Macroeconomic Time Series Facts: The Effects of Monetary Policy. European Economic Review, 36(5):975-1000; [22]Wulandari, R. (2012), Do Credit Channel and Interest Rate Channel Play Important Role in Monetary Transmission Mechanism in Indonesia? : A Structural Vector Autoregression Model. Procedia - Social and Behavioral Sciences, (65), 557 - 563; 
Yusuf Ekrem Akbas, Canan Sancar

[23]Yilanci, V.,Tunali, Ç.B. (2014), Are Fluctuations in Energy Consumption

Transitory or Permanent? Evidence From A Fourier LM Unit Root Test.

Renewable and Sustainable Energy Reviews, (6), 20-25.

APPENDIX

Appendix 1. Table for the firm costs in Turkey

\begin{tabular}{|l|l|c|}
\hline Cost Items & Context & $\begin{array}{l}\text { Share among the total } \\
\text { Expenses (\%) }\end{array}$ \\
\hline Cost of the good sold & $\begin{array}{l}\text { Local and imported raw } \\
\text { materials and material } \\
\text { expenses, electricity - gas - } \\
\text { water expenses, labour } \\
\text { expenses. }\end{array}$ & \\
\hline Operating Expenses & $\begin{array}{l}\text { General management } \\
\text { expenses, marketing, selling } \\
\text { and distribution expenses, } \\
\text { R\&D expenses, etc. }\end{array}$ & \\
\hline Financing Expenses & Interest, comission etc. & 8,5 \\
\hline Other Expenses & $\begin{array}{l}\text { Other expenses other than } \\
\text { the ones mentioned above. }\end{array}$ & 2,2 \\
\hline
\end{tabular}

Source: Central Bank of the Republic of Turkey, 2016.

\section{Appendix 2. CPI and PPI rates in Turkey}

\begin{tabular}{|l|l|l|}
\hline 2015 & CPI (\%) & PPI (\%) \\
\hline January & 7.24073 & 3.27804 \\
\hline February & 7.54669 & 3.09554 \\
\hline January & 7.61025 & 3.41482 \\
\hline April & 7.91280 & 4.79973 \\
\hline May & 8.09299 & 6.52043 \\
\hline June & 7.20453 & 6.73131 \\
\hline July & 6.81416 & 5.62205 \\
\hline August & 7.14051 & 6.21342 \\
\hline September & 7.94699 & 6.92207 \\
\hline October & 7.58143 & 5.73822 \\
\hline November & 8.10224 & 5.25142 \\
\hline December & 8.80833 & 5.71150 \\
\hline Source Cental Bank & \\
\hline
\end{tabular}

Source: Central Bank of the Republic of Turkey, 2016. 